international institute for RESEARCH MEMORANDUM

\title{
A SYSTEMS ANALYSIS APPROACH TO NUCLEAR FACILITY SITING
}

Jacques G. Gros, Rudolf Avenhaus, Joanne Linnerooth

Philip D. Pahner, and Harry J. Otway

December 1974

SCHLOSS LAXENBURG
2361 LaXenburg

AUSTRIA 

$R M-74-29$

A SYSTEMS ANALYSIS APPROACH TO NUCLEAR FACILITY SITING

Jacques G. Gros, Rudolf Avenhaus, Joanne Linnerooth Philip D. Pahner, and Harry J. Otway

December 1974

\begin{abstract}
Research Memoranda are informal publications relating to ongoing or projected areas of research at IIASA. The views expressed are those of the author, and do not necessarily reflect those of IIASA.
\end{abstract}



A Systems Analysis Approach to Nuclear Facility Siting ${ }^{1}$

Jacques G. Gros ${ }^{2}$, Rudolf Avenhaus ${ }^{2}$, Joanne Linnerooth ${ }^{3}$, Philip D. Pahner ${ }^{4}$, and Harry J. Otway ${ }^{5}$

\section{Summary}

In recent years there has been a growing tendency in science to conduct multi-disciplinary studies of largescale systems. These studies include the entire spectrum of economic, technological, environmental and societal factors which characterize the complex problems of advanced industrialized societies. One of the more promising ways of addressing these problems is the broad research strategy of applied systems analysis. Basically this is a rational approach to problem-solving which attempts to identify and model interactions between the systems under study and all other systems. This results in a thorough understanding of the system being studied which may then serve as an aid in decision-making. This paper attempts to demonstrate an application of the techniques of systems analysis, which have been successful in solving a variety of problems, to the question of nuclear facility siting.

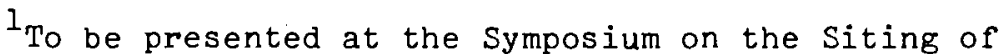
Nuclear Facilities, International Atomic Energy Agency, Vienna, Austria, December 9 to 13,1974 . The views expressed in this paper are those of the authors and do not necessarily reflect those of the organizations with which they are affiliated.

2 International Institute for Applied Systems Analysis, Energy Systems Project.

${ }^{3}$ International Institute for Applied Systems Analysis, Joint IAEA/IIASA Project.

4 International Institute for Applied Systems Analysis, Joint IAEA/IIASA Project; present address, Naval Regional Medical Center, Camp Pendleton, California, U.S.A.

${ }^{5}$ Project Leader, Joint IAEA/IIASA Research Project, Division of Nuclear Safety and Environmental Protection, International Atomic Energy Agency. 
Within the framework of an overall regional land-use plan, a methodology for establishing the acceptability of a combination of site and facility is discussed. The consequences (e.g., the energy produced, thermal and chemical discharges, radioactive releases, aesthetic values, etc.) of the site-facility combination are identified and compared with formalized criteria in order to ensure what might be called "legal acceptability". Failure of any consequences to satisfy standard requirements results in a feedback channel which works to effect design changes in the facility.

When "legal acceptability" has been assured, the project enters the public sector for consideration. The responses of individuals and of various interested groups to the external attributes of the nuclear facility gradually emerge. The criteria by which interest groups judge technological advances reflect both their rational assessment and unconscious motivations. This process operates on individual group, societal and international levels and may result in two basic feedback loops: one which might act to change regulatory criteria; the other which might influence facility design or site selection. Such reactions and responses on these levels result in a continuing process of confrontation, collaborative interchange and possible resolution in the direction of an acceptable solution. Finally, a Paretian approach to optimizing the site-facility combination is presented for the case where there are several possible combinations of site and facility. A hypothet1cal example of the latter is given, based upon typical preference functions determined for four interest groups.

The research effort of the IIASA Energy Systems Project and the Joint IAEA/IIASA Research Project in the area of nuclear siting is summarized. 


\section{Prescreening}

The literature on prescreening of potential nuclear facility sites is reviewed as a background for a proposed model for optimizing a combination of site and facility. The properties of the model are discussed in detail and a hypothetical example is presented.

A rigorous systems analysis of a nuclear plant siting decision requires that the number of options be finite. Therefore, before analysis can start, a finite number of possible sites must be selected in the region where a plant is to be established. As this prescreening is done well over 10 years before a nuclear plant comes on line, longterm aspects such as regional development have to be taken into account. Prescreening includes the following steps:

1) consideration of large regions as a whole,

2) determination of acceptable zones in these regions,

3) specific site studies.

Step 1 is done with the help of extended data bases including population densities, meteorology, geology, seismology, water flows, etc., and may even include aerial surveys. (See,e.g., Carlbom et al. [1] for a nation and Hunt [2] for a region.) The end product of this kind of analysis is either a number of acceptable regions or a list of specific sites. Note that not only the service area of the utility must be considered but also the total region and even offshore sites.

In step 2 one first identifies zones which are completely unacceptable in one or more respects (e.g., the site being in an earthquake zone). Thereafter one considers all the other consequences. One common method of analysis is the use of overlays colored according to the value of specific consequences: where colors are too strong the area is eliminated from consideration. These non-quantitative techniques usually are supervised by experienced decision-makers.

Step 3 is treated in a similar way as step 2 in the sense that unacceptable sites are excluded. One may then arrive at a finite number of acceptable sites, which is the starting point for a quantitative analysis. 


\section{Systems Model}

\section{A. Literature}

The importance of the problems of appropriate selection of a site for a nuclear facility is best illustrated by the frequent international conferences devoted to this subject (e.g., those of the IAEA and of the ANS [3] [4] [5] [6]); in fact this conference is just another example.

Let us assume that a limited number of sites have been selected by the prescreening, procedure described in the foregoing section. Then any systematic study of a siting problem starts with a list of consequences important in selecting a specific sited. This list has been established many times. The authors have found close agreement among these lists, irrespective of the nationality of the authors (see, for instance, [7] [8] [9] [10]).

A natural next step would be to devise an evaluation matrix where one simply puts plus and minus signs against the desirability of a site with respect to the criteria being considered (see Hill and Altermann [11]). A more sophisticated way would be to put values on the attributes (e.g., Beer [12]). Sites unacceptable in any one respect could thus be eliminated.

After these preliminary steps, cost figures must be analyzed, including cost of land needed, equipment and maintenance for meeting environmental standards (see,e.g., the EPA work [13]), power transmission, etc. Cost benefit may he considered without explicit attention to other benefits. In many cases the fact that cost figures are not known accurately must be taken into account. Initially these studies were made only from the point of view of the utility companies; examples are given by Anderson [14]. However, with growing public interest in nuclear plants, a siting decision becomes a matter in the public domain; therefore it became necessary to model the impact of different interest groups on these decisions. An approach using decision analysis has been outlined by Keeney and Na1r [25]; previously, a similar approach, and extensions, had been done by Gros [15]. In Section IV an example is discussed which is based on the work of Gros. In the International Institute for Applied Systems Analysis, work is continued along these lines. A critical review of nuclear facility siting techniques is near completion at the Institute [16]. 


\section{B. The Model}

Figure 1 is a schematic representation of the flow of information involved in judging the acceptability of a sitefacility combination. This diagram intends to plot the real, practical flow of information, rather than the perceived flow, and is highly rationalized and simplified in order to serve as a discussion aide.

Box 1, Fig. 1, represents the possible combinations of Site $\left(S_{k}\right)$ and Facility $\left(F_{j}\right)$ which might be proposed. A decision to propose any combination of site and facility carries with it a number of implied consequences which include, in addition to the primary benefits intended by the sponsor (e.g., electrical power), a number of side effects. These side effects, which may be adverse or beneficial, include: radioactive, chemical and thermal discharges; accident hazards; aesthetic effects; noise, etc.

In addition to the set of primary and secondary consequences beingsatisfactory to the sponsor (industry or governmental agency, depending upon the country), they must also satisfy any formal regulations governing these effects. This comparison (Box 3 ) would be made by some regulatory body which uses the criteria shown in Box 2. If the consequences of the site-facility combination compare favorably with the respective criteria, then the proposal can be said to meet. the requirements of "legal acceptability". Failure to satisfy the criteria results in the postulated feedback loop shown in Fig.l, which acts to change the site-facility characteristics until the criteria can be met. If the changes required make the proposal unacceptable to the sponsor, it would be abandoned and a new proposal submitted to the regulatory body.

When the line of "legal acceptability" has been crossed, we can say that the proposal, for practical purposes*, first enters the public sector where acceptability is judged on a quite different basis.

* "for practical purposes" because it is clear that the public can start forming their opinions before legal acceptability has been determined. However, unless regulatory criteria are satisfied, any judgments made in the public sector may be considered premature. 
Here the responses of individuals, and of various interested groups, to the consequences implied by a site-facility combination gradually emerge. Interest groups use multiply determined criteria to judge, and perhaps challenge, technological advances; that is, their preferences (Box 4 ) reflect their rational assessment of the facts (consequences) as they know them, their perception of these consequences (Box 5), and the effects of factors which may be buried deep in the nature of the groups themselves--i.e., unconscious fears and motivations, group dynamics. These preferences are formed, in part, in the light of the past experiences of the individual and group.

It is important to note that this complex process operates on many organizational levels: the individual, the Eroup, the societal or national, and perhaps even the international. In Figure 1 a number of interest groups is postulated which includes all these levels of interest. Box 6 shows the process of comparison which has been described. Here, the acceptability of the site-facility combination to each group must be considered. In addition, by some unspecified process, the individual group's preference comparisons influence the final decision.

Here two feedback loops have been suggested: one which might act to change facility design, or site selection, if the comparison is unfavorable; another which might affect the regulatory criteria. These reactions and responses, on these many levels, result in a continuing process of confrontation, collaborative interchange and eventual resolution. In the following sections the consequences of site-facility combi nation and the individual boxes of Figure 1 will be discussed in more detail. 


\section{Discussion of Figure 1}

\section{A. Selection of the Site and Facility}

We have said that the first box of Fig.l represents possible site $\left(S_{k}\right)$ and facility $\left(F_{j}\right)$ combinations from which the sponsor may choose. These cholces are to some degree interdependent and for this reason appear on the diagram together. It is assumed that the prescreening has previously narrowed the site selections to include only those candidates which have no "unacceptable" characteristics; a further comparison of these candidates is now made to determine the "best" site. In a similar fashion the facility designs are compared according to specific criteria set by the sponsor. To illustrate this process, a few of the possible considerations involved in the siting and design of a nuclear power plant will be discussed. The analysis is easily generalized to include fuel fabrication plants, fuel reprocessing plants, and other nuclear facilities.

After prescreening, the sponsor must determine the "most preferred" of the candidate sites. The usual basis of this decision is the sponsor's ranking of the site characteristics. Listings of these characteristics are well documented in the literature and generally include the locational requirements, site-related economic factors, and environmental considerations.

The characteristics of a potential site include the ease of land acquisition, zoning, the ease of transporting major reactor components to the site, the proximity of transmission facilities, and distance to the load. The site geology and hydrology--including foundation conditions, location of faults, stability of subsurface materials, and velocity and availability of a cooling water source--are important considerations. The possibility of flooding, landslides, and severe storms should also be considered.

Economic considerations include the costs of land acquisition, site preparation, material transportation and energy transmission. The location of the site has a direct impact on specific costs of the facility, such as the extent of safeguards and the type of cooling system.

Included in the environmental impact considerations are the population density and the proximity of population centers. Meteorological factors, such as the influence of the topography and special atmospheric conditions on the different paths of effluents, are also important. In addition, regional land use must be considered. Some of the more sensitive areas include park lands, wilderness and recreation areas, historical sites, wildlife habitats and military installations. 
A few of the many other significant factors are the aesthetics of the site, the use of natural resources, and the disruption of local communities.

In choosing, a facility design, power plant sponsors will endeavor to ensure reliable service at minimum per unit power cost, given constraints imposed by regulatory authorities and the site itself. More specifically (avoiding any attempt at compreilensiveness), the considerations involve a choice of reactor type and peripheral equipment: cooling, system, intake and discharge systems, chemical and sanitary waste handling: systems, biocide treatment system, and so forth. There are usually several available technologies. For example, in the choice of cooling system the technological alternatives are once-through cooline, mechanical and natural draft wet and dry cooling towers, cooling ponds, spray ponds, and spray canals.

\section{B. Consequences}

Various consequences, labeled $A_{q}$ (see Fig.l), result from the selection of the site, $S_{k}$, and the facility $F_{j}$. Since the nuclear power plant, at this point in the analysis, has not yet been constructed, most of these consequences are perceptions of some future occurrence. The accuracy of these perceptions depends on the available information and will differ among the interested individuals. But since continuation of the project will depend, in part, on these perceptions, they should be fully anticipated. Only a brief discussion of a few of the more important perceived consequences of the siting and facility decisions can be included in this paper. The purpose is only to introduce the reader to the sort of factors that should be included at this stage of the analysis.

Consequences evolve from three stages in the development of the nuclear power plant: site selection, plant construction, plant operation. They might include, for example, land speculation after the siting decision, community disruption during the construction period, and regional development during plant operation. They impinge on local residents, users of the power, and in $a$ vague sense regional and national interests.

Local communities are most directly affected by a siting decision, and immediately so where there is dislocation of local residents. Then there is disruption from plant construction. During operation of the plant the primary impacts include radioactive discharges, thermal pollution and 
aesthetic degradation of the landscape. In addition, local residents will be anxious over the possibility of a nuclear accident; and they might perceive a threat of further industrialization of the area as a result of the nuclear power plant. The extent to which these impacts are perceived by the local residents as real dangers and, thus lessen the desirability of locating in an area, could be reflected in lowered property values. However, the actual direction of the change in property values is unclear, since lowered local property tax rates due to the increase in the tax base could increase property values.

In some cases more specific impacts of a consequence, often referred to as attributes, should be considered. (Finding, the set of attributes is a very important and difficult step in the analysis.) For example, the impact of a radioactive release includes the possibility of gene mutations and an increased cancer rate in human beings, and of danger to local agricultural and fishing interests. The extent of this potential damage is dependent upon a complicated set of factors, e.g., type of isotope release, atmospheric conditions for effluent transmission, pathways for radioactive effluent absorption, and effects of this absorption on various forms of life. Another possibility, damage from thermal pollution, depends upon the type of abatement equipment used. The most serious pollution results from the once-through system, where the condenser cooling water is taken from a nearby river, lake, estuary or ocean and then (usually) returned to the same source. This procedure results in some modification of the aquatic environment; an increase in water temperature changes the physical properties of water such as density, viscosity, and gas solubility, which can affect such phenomena as the vertical migration of plankton and the mobility of higher organisms. Also any change in the eco-system equilibrium. can have other effects on higher organisms.

\section{Criteria}

As already mentioned, the levels of the consequences discussed must satisfy certain criteria which may exist for regulating these consequences.

There are two different types of criteria: those specifying the limits within which certain consequences have to be kept, and those of a qualitative nature which represent only general guidelines. Examples for the first type are regulations governing the normal operational releases of radioactive isotopes into air or water, or the outlet temperature of cooling water into a river in the case of 
once-through cooling of a power station. Examples for the second type are acceptable upper limits for the radioactive releases in accidental situations, or population densities around nuclear plants; in these cases values have been traditional rather than stated in formal standards.

Determining the values of the criteria requires a careful analysis of the consequences: for example, in the use of normal operational radioactive releases one must analyze what ambient dose rates result from what emissions, taking into account biological pathways, etc. Such studies, made with great care (see,e.g., Pochin [17]), have resulted in standards for all kinds of radioactive isotopes recommended by the International Commission for Radiological Protection (ICRP). With increasing knowledge of the biological effects of radionuclides, these standards have changed: whereas in 1930100 rem per year were thought permissible, in 1957 this value was reduced to 5 rem per year. The reculatory bodies inversely take these ICRP recommendations as a basis for determining the emission standards for a specific plant, where site characteristics such as geology, and main wind speed and direction, now have to be taken into account.

Regulations also exist for the outlet temperature of the cooling water, but there are no international standards: the local authorities limit the maximum temperature increase as a function of the total amount of water available, weather conditions, etc.

For accidental radioactive releases the situation is not so clear: consequences are being considered even in monetary terms (see Beattie [18]), but no standards have yet resulted. Unofficially, the value of 25 rem per accident and human lifetime is sometimes stated. Many of the issues are covered in a paper by Majone [19].

Only general rules exist for permitted population densities around nuclear facilities. So far in the Federal Republic of Germany, for example, the following average values have been observed for nuclear power stations (see the IRS work [20]):

$\begin{array}{lr}\text { up to } 5 \mathrm{~km}: & 10000-15000 \text { people, } \\ \text { up to } 10 \mathrm{~km}: & 30000-50000 \text { people, } \\ \text { up to } 20 \mathrm{~km}: & 100000-200000 \text { people. }\end{array}$

Already, however, in one case (Biblis [2l]) these values have not been observed; in general, nuclear plants are tending to come closer to cities. 


\section{Interest Groups}

Once the consequences of a siting decision meet the standards of the regulatory agency, the siting process moves into the public sector. Here the perceived consequences are measured against the criteria of various "interest groups". This is probably the least understood stage of the siting decision, and it is here that behavioral scientists can contribute to the analysis.

The psychologist views the interest group as a confluence of social systems including individual responses, societalcultural factors, political-economic influences, and the input of the scientific community. The interest group per se represents the focal point of the interactions of these various systems.

A unique feature of nuclear energy is its tremendous potential for both constructive and destructive utilization. It is perhaps this factor that in part accounts for the difficulties sometimes encountered in the public response to the siting of such facilities. The population may respond on an emotional-irrational level, with fear of nuclear holocaust and annilihation, worry about genetic effects and future generations, anxiety due to lack of adequate knowledge and conceptualization of the power of the atom.

Assuming, then, that nuclear energy is a fear-provoking stimulus, we can examine the response of the individual personality. We owe much of our understanding of the dynamics of personal responses to in-depth psychology. A helpful generalization is that external dangers lead to fear, which in turn leads to a variety of healthy or unhealthy defenses against this fear. The two most primitive are flight and fight--apathetic withdrawal physically and emotionally or denial that any threat exists, or a readiness to retaliate. It is the latter response that accounts in part for the opposition of the group to what is perceived as an external threat.

External dangers are not the only dangers in life for the human being; there are internal dangers as well. As the internal security and intra-psychic balance of an individual is eroded, fear and anxiety mount. Thus resistance to the siting of nuclear power facilities may be due in part to projection of our internal fears onto a symbolic external object, the facility. As these fears are expressed, the individual finds others who think and act similarly.

The social psychologist now provides further insights-based on observations of group dynamics and laboratory studies-into the nature of group responses. An interest group reflects 
to varying degrees elements of its members' individual responses, characteristics of the larger societal-cultural group of which it is a part, and an indication of the information it has obtained from the scientific-technological community; and the political milieu will influence the character of the resistance. The group per se, however, has its own unique characteristics. A large body of literature supports the following conclusions: a) interest groups tend to emerge and crystalize around affect-laden social-environmental concerns; b) groups tend to be solution-oriented rather than problem-oriented; that is, they gravitate toward a dialectic-adversary position rather than engage in collaborative exchanges; c) the constitution and cohesiveness of a group is likely to be directly related to the degree to which its members share similar values and attitudes; d) communication patterns are often distorted, especially in groups with a vertical hierarchy of status and power; e) new information is accepted or rejected contingent on the support it provides for the beliefs and values of the group; $f$ ) behavioral responses of members are influenced by those of other members, and the strength and integrity of individual values are weakened. Thus the interest group opposing the siting of a nuclear facility is likely a well-organized, firmly entrenched, emotional body of persons committed to their position and screening factual information according to the utility it has for their position. Of interest of course is that their counterparts are frequently matched feature for feature.

On the final level the interest group is viewed in its larger context, the societal-cultural milieu from which it springs. The anthropologist and historian are now consulted for their insights. Certainly the fervor and diversity of movements in recent years have been remarkable. Perhaps this is evidence of a larger-scale, more generalized response to the ever-expanding technologies. Analysis of previous technological revolutions suggests that there gradually evolves a social structure which begins to put the brakes on the process. In that sense the interest group becomes a culturally determined, expected response which emerges at the interface of the individual faced with survival and the entire technological-societal-political-cultural maze.

We have seen that the siting of a nuclear power facility is a complex technological, economic, socio-political, environmental, and psychological issue. Hopefully, collaboration and interchange among those involved in the above-mentioned disciplines will facilitate the process of making rational decisions in the best interest of the community. 
IV. The Paretian Approach

\section{A. Introduction}

In the last section we discussed many of the impacts that are important in the siting of nuclear power plants, and the interest groups that influence the final decision. Now we shall show how all these inputs can be integrated into one mathematical analysis. The underlying assumption is the concept of Pareto optimality. A Pareto-admissible decision is one from which any technologically feasible change would make at least one of the interest groups worse off; in other words, if one makes a Pareto-admissible decision, it is impossible to make one interest group better off without making another worse off. The mathematical analysis that finds the set of Pareto-admissible decisions is often called Paretian environmental analysis. The basic concepts were pioneered by Dorfman and Jacoby [22]; Gros [23] extended the work to nuclear power plant siting decisions and showed how utility function analys is could be integrated into the framework of Paretian analysis. In addition to describing the mathematical analysis, we will discuss how these results can be used for descriptive, predictive, or prescriptive purposes.

\section{B. Mathematical Model}

Let us assume that the required number of new generating units in a region, $R_{1}$, is known for each year of a planning horizon, $1=0,1, \ldots, M$. Further let there be $K$ sites available, each of which can support a certain number of generating units. The problem is then to find the set of Pareto-admissible unit designs and unit deployments.

'The first step, after identifying the problem, is to determine which interest groups influence the decision. Once the groups have been identified, a set of attributes for each group should be found which describes what is important to that group. Let $x_{n i}$ be the $n^{\text {th }}$ attribute for the $i^{\text {th }}$ group.

For instance, for those groups concerned about radiation effects, one or more of their attributes should cover this effect. For each interest group, a utility function should be estimated which describes the relative preferences for different unit designs and unit deployments. In addition, a set of technological relations should be found which relate unit design parameters (such as size and type of cooling system, reactor type, etc.) to the attributes. 
A utility function is a monotonic function of a group's preferences with the property that the expected value of the utility function is a guide for decision making. Let

$$
\mathrm{u}_{\mathrm{kl}}^{\mathrm{imn}}\left(\mathrm{x}_{\mathrm{ni}}\right)
$$

be the utility function for the $n^{\text {th }}$ attribute for the $i^{\text {th }}$ interest group for site $k$ and year $m$, given that a unit of some design was commissioned in year 1 .

Each single attribute utility function is found from a set of indifference questions, and each function is generally scaled from 0 , for the least-preferred value of the attribute, to 1 for the most-preferred value

$$
0 \leq U_{k l}^{i m n}\left(x_{n i}\right) \leq 1
$$

But each group's preferences depend on more than just one attribute. Therefore, let $\underline{x}_{i}=\left(x_{1 i}, x_{2 i}, \ldots, X_{N i}\right)$ be the set of attributes of the $i^{\text {th }}$ interest group which describes what is important to this group in siting decisions. For this. set of attributes, a multi-attribute utility function, $\mathrm{U}_{k l}\left(_{-i}\right)$ should be estimated. Based on the group's preference structure, this multi-attribute utility function could have one of several special forms. For instance, if certain independence properties of preferences hold, then the multi-attribute utility function can be written in the pure product form as follows (Keeney [24]):

$$
1+\mathrm{d} \cdot \mathrm{u}_{\mathrm{kl}}^{\mathrm{im}}\left(\underline{x}_{i}\right)=\prod_{n=1}^{N}\left(1+\mathrm{d} \cdot \mathrm{d}_{\mathrm{n}} \cdot \mathrm{u}_{\mathrm{kl}}^{\mathrm{imn}}\left(\mathrm{x}_{n i}\right)\right),
$$

where $d$ and the $d_{n}$ 's are scaling constants which satisfy

$$
\begin{aligned}
& 0 \leq d_{n} \leq 1 \text { for } 1 \leq n \leq N,-1 \leq d, \sum_{n=1}^{N} d_{n} \neq 1 \\
& \text { and } 1+d=\prod_{n=1}^{N}\left(1+d \cdot d_{n}\right) .
\end{aligned}
$$

Naturally, if other preference structures are to be modeled, then the multi-attribute utility function will have a different, and generally more complicated, form.

In addition to the preference structure for these attributes, an interest group is concerned with when a unit is commissioned. Therefore, a multi-time-period utility function $\mathrm{Ui}_{\mathrm{k} l}^{i}$ should be obtained for each interest group. A common form for this function, given the multi-attribute utility function for each time period, is as follows: 


$$
1+c \cdot U_{k l}^{i}=\prod_{m=0}^{M}\left(1+c \cdot c_{m} \cdot U_{k l}^{i m}\left(\underline{x}_{i}\right)\right),
$$

where $c$ and the $c_{m}$ 's are scaling constants with:

$$
0 \leq c_{m} \leq 1 \text { for } 0 \leq m \leq M,-1 \leq c, \sum_{m=0}^{M} c_{m} \neq 1
$$

and $1+c=\prod_{m=0}^{M}\left(1+c \cdot c_{m}\right)$.

A reasonable criterion for the power plant siting problem when more than one interest group is involved is to find the set of Pareto-admissible solutions. In order to find such solutions, objective function values of the following form can be used:

$$
\begin{aligned}
& U_{k l}=\sum_{i=1}^{I} w_{i} U_{k l}^{i}, \\
& 0 \leq w_{i} \leq 1, \quad \text { for } 1 \leq i \leq I, \quad \sum_{i=1}^{I} w_{i}=1 .
\end{aligned}
$$

The values wi are referred to as political weights since they give some indication of the distribution of benefits from a siting decision. (If more than one technology can be used at a site, then the technology that maximizes $\mathrm{U}_{\mathrm{kl}}$ is the Pareto-admissible unit design.) The objective function for the deployment decision can be expressed as follows:

$$
\sum_{k=1}^{K} \sum_{l=0}^{M} U_{k l} \cdot Y_{k l}
$$

where $\mathrm{Y}_{\mathrm{kl}}=0,1 ; 0$ if the site is not committed in year 1 , and 1 if the site is committed in that year. This objective function should be maximized subject to the constraint that the number of sites committed in each year should equal the number needed, $R_{1}$, and that each site is committed only once. Mathematically, this can be written:

$$
\begin{array}{ll}
\sum_{k=1}^{K} Y_{k l}=R_{l}, & \text { for } 0 \leq 1 \leq M, \\
\sum_{l=0}^{M} Y_{k l}=1, & \text { for } 1 \leq k \leq K
\end{array}
$$


Everything was certain in the model just described; for instance, the number of sites that must be committed in each year was exactly known. But in real life, many quantities are not known exactly but can only be predicted in terms of a probability density. For instance, an electric utility company may need either 3 or 4 new nuclear units in 1985, with an equal probability of either value being correct; or regulatory standards cannot be predicted with certainty, but a distribution of possible standards may be predictable. One advantage of using utility functions is that these uncertain situations can be modeled easily, since the expected value of a utility function is a guide for decision-making. Details of modeling these uncertain situations, along, with information on the utility function assessment process, can be found in the papers by Gros [15], [23].

\section{Hypothetical Example}

We will illustrate the ideas outlined above with a hypothetical example based on a study of nuclear power plant siting in New England [15]. Let us assume that the technological alternatives are fixed (in the example, once-through cooling and spray canals for coastal sites). Based on a careful analysis of the political, societal and economic situation in the region under consideration, the following broad interest groups which have a major influence on siting decisions have been identified:

1) Electric utility companies

2) Regulatory bodies

3) Groups concerned with environmental, aesthetic and similar problems (not necessarily local groups)

4) Local interest groups.

The last interest group, for instance, is concerned about the general welfare of the region around each site.

In order to obtain a multi-time-period utility function for each of these groups, a series of interviews are necessary. The first several would try to establish qualitatively what is of concern to the groups, try to obtain the set of attributes, and try to identify someone who can quantitatively describe the preferences of the group when the utility function is assessed. For instance, for the electric utility companies interest group, the following four attributes cover many impacts of importance in the choice of sites:

1) number of units at a site

2) cost

3) population within 10 kilometers of a site

4) incremental water temperature at peak ambient water temperature period of year. 
A set of typical single attribute utility functions is shown in Figure 2. The first attribute, number of units at a site, covers the perceptions of the electric utility companies on the ease of obtaining regulatory approval for a different number of units at a site; it also covers effects on system reliability of having a different number of units at a site. To illustrate the type of indifference question used in the assessment, let us consider the second attribute, cost. As can be seen from the figure, the most preferred cost, $\$ 500 \mathrm{M}$, has a utility value of 1 ; the least preferred cost, $\$ 650 \mathrm{M}$, has a utility value of 0 . Let us look at a lottery in which there is a 50\% chance of obtaining a $\$ 500 \mathrm{Mi}$ unit and a $50 \%$ chance of obtaining a $\$ 650 \mathrm{M}$ unit. The expected utility value for that lottery is .5 $\mathrm{U}(\$ 500 \mathrm{M})+.5 \mathrm{U}(\$ 650 \mathrm{M})=$ $.5 \cdot 1+.5 \cdot 0=.5$. Now let us assume that the assessor was indifferent to the choice between having a unit costing $\$ 590 \mathrm{M}$ for certain and having the lottery. Then the utility value of $\$ 590 \mathrm{M}$ is .5 , since this cost is indifferent to a lottery with an expected utility value of .5 . (Remember that the expected value of the utility function is a guide for decision-making.) ' In this situation, the value the assessor is willing, to take for certain, $\$ 590 \mathrm{M}$, is less preferred than the expected value of the lottery $(\$ 575 \mathrm{M})$. This behavior is common and the assessor is said to be riskaverse over monetary costs. The analyst would ask similar indifference questions, building up the utility function from its component parts.

The result of the analysis is a set of Pareto-admissible decisions. The model does not identify one best decision, for there is no one best decision from a political decisionmaking viewpoint. The results can be used from a descriptive, predictive, and prescriptive viewpoint. As a descriptive tool, the Paretian model can be used to organize information and to help identify what is happening during decision-making. The advantage of this type of analysis is that it forces the analyst to consider explicitly the important interest groups that influence the decision. To test the model as a predictive tool, the analyst determines whether the actual decision is Pareto-admissible. The use of the model as a prescriptive tool is more action-oriented than the other uses. Here, the Pareto-admissible solutions can be used in the actual decisionmaking process. Alternatively, if a Pareto-inadmissible decision is made, the analyst can offer for consideration an admissible decision which would make one group better of without making any other group worse off. We think that the Pareto-admissible one would be chosen over the Pareto-inadmissible one. 


\section{Concluding remarks}

Work is being done at the International Institute for Applied Systems Analysis and by the Joint IAEA/IIASA Research Project on nuclear facilities siting issues. We have already mentioned that a thorough review of contrasting siting methodologies with critical comparative comments is being done at the Institute. An aim of their larger project is to indicate more clearly the interrelationships between decisions which must of necessity be made at different levels and by so doing delineate clearly those problems which are not part of the siting process per se. The Institute's work will extend Paretian analysis and will emphasize close coordination between methodological studies and carefully planned and executed public attitude assessment. Their study of a specific siting problem will attempt to incorporate rigorous risk perception work with decision methodologies that include the broad spectrum of impacts.

The Joint IAEA/IIASA Research Project is an international, interdisciplinary group with the task of studying risk assessment principles and their application in judging the acceptability of technological innovations. The focus is on energy production systems, and more specifically on nuclear energy as an interesting case study providing virtually all of the variables which are of interest in risk assessment studies. The research interests of the Joint Project, and its sponsors, lie primarily in the application of risk assessment principles to standard setting, the study of the perception of risks of a technological origin, methodologies for determining societal preferences for risk acceptance and the group dynamics and information transmission involved in making societal judgments on technological applications. Within this framework the immediate research plans include: 1) a study of the estimation procedures used in determining the probabilities of certain outcomes or risks, 2) the value society puts on these risks (in the framework. of modern utility theory), 3) the relationship of these values to standard setting procedures, and more generally 4) the capacity of societies, both traditional and modern, to cope with technological risks. Longer term research plans include the development and application of techniques to understand and estimate individual and group perception of different types of risk including those of a technological origin. 


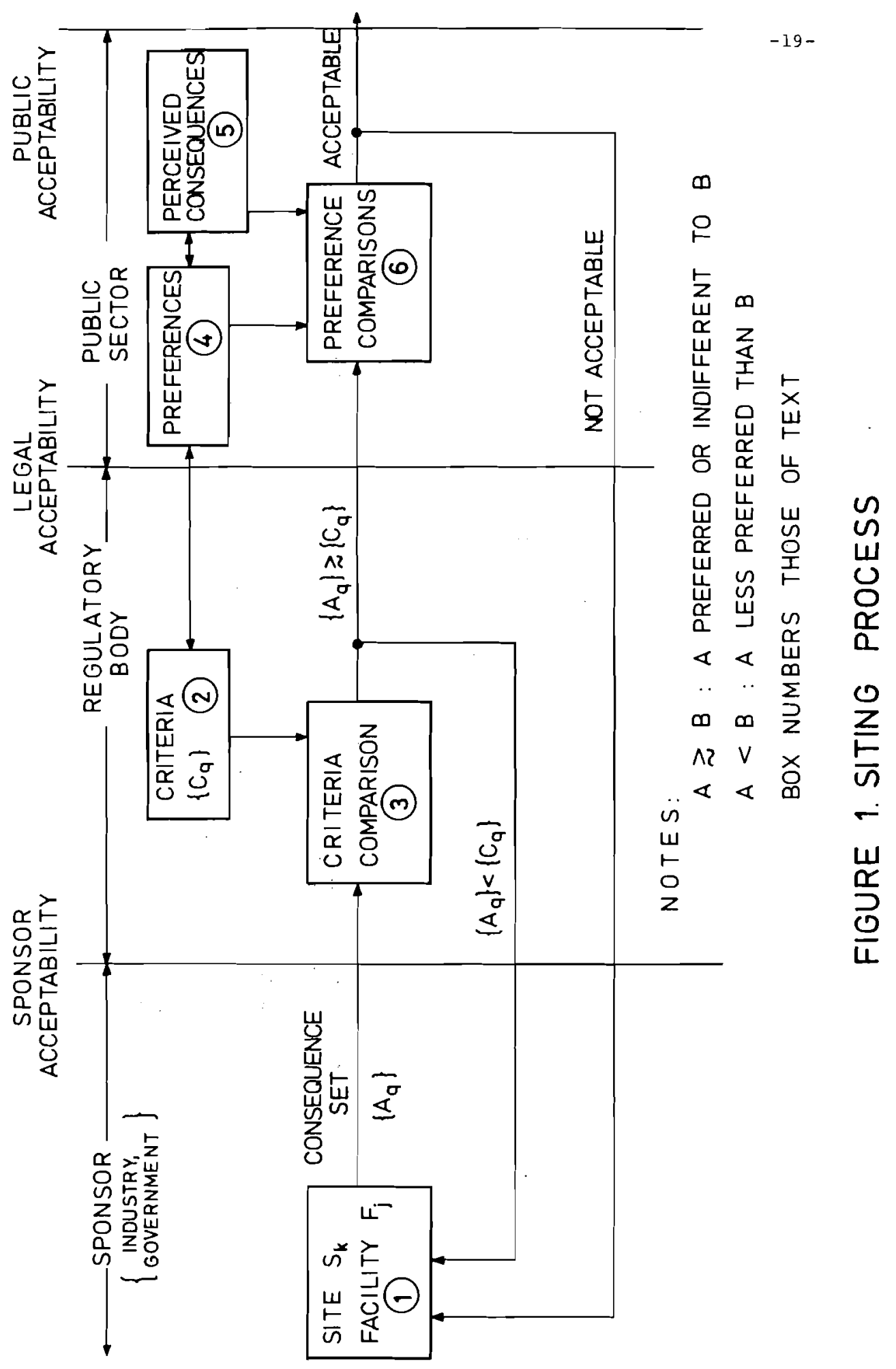


$U_{k 1}^{m 1}\left(x_{19}\right)$

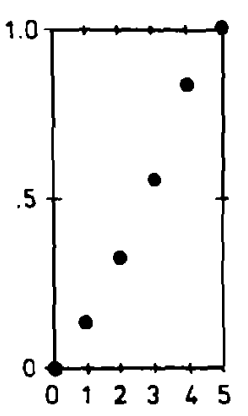

$x_{11}$ : NUMBER OF UNITS AT A SITE

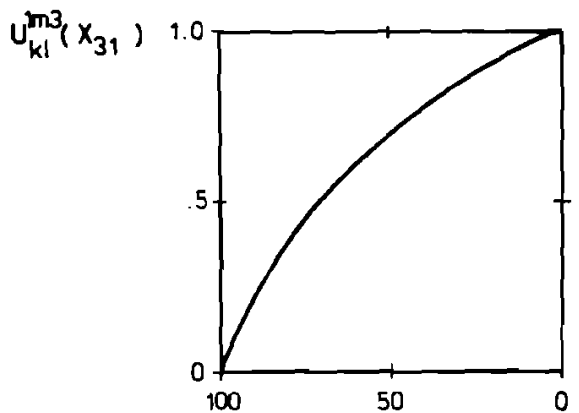

$x_{31}$ :POPULATION WITHIN 10 KILOMETERS OF A SITE(NTHOUSANDS)

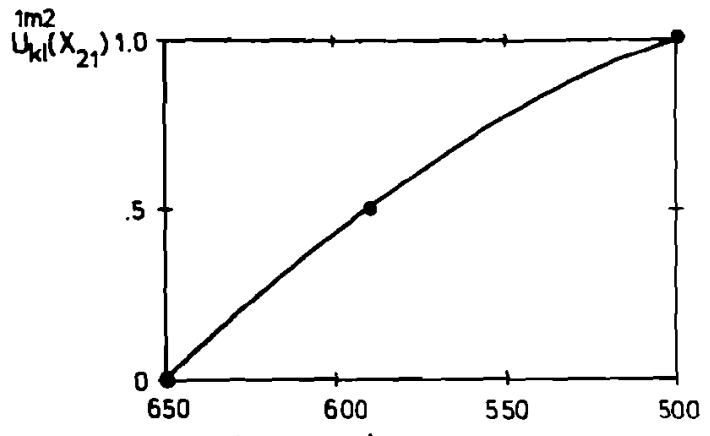

$x_{21}:$ COSTS $(\$$ MILLIONS )

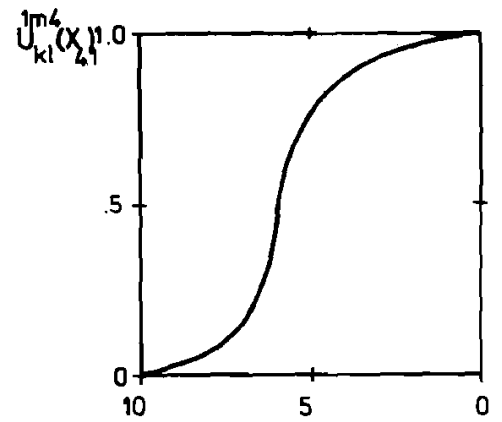

$X_{L 1}$ : NCREMENTAL WATER TEMPERATURE $\left({ }^{\circ} \mathrm{C}\right)$ AT PEAK AMBIENT WATER TEMPERATURE PERIOD OF YEAR

FIGURE 2. SINGLE-ATTRIBUTE UTILITY FUNCTIONS FOR ELECTRIC UTILITY COMPANIES INTEREST GROUP ( $i=1)$ 


\section{References}

[1] Carlbom, L., Obradovic, J., and L. Mojovic. Analys is of Criteria and their Application in site section for Nuclear Power Plants in Yugoslavia. In Containment and Siting of Nuclear Power Plants. International Atomic Energy Agency, Vienna, 1967, pp 171-181.

[2] Hunt, F.R. Power Station Site Selection in England and Wales. In Environmental Aspects of Nuclear Stations. International Atomic Energy Agency, Vienna, 1971, pp. 647-659.

[3] International Atomic Energy Agency. Siting of Reactors and Nuclear Research Centers. Proceedings of a Symposium of the IAEA, Bombay, 1963.

[4] International Atomic Energy Agency. Containment and Siting of Nuclear Power Plants. Proceedings of a Symposium of the IAEA, Vienna, 1967.

[5] International Atomic Energy Agency. Environmental Aspects of Nuclear Power Stations. Proceedings of a Symposium of the IAEA in cooperation with USAEC, New York, 1970.

[6] American Nuclear Society. Transactions of the American Nuclear Society Conference on Nuclear Power Plant Siting, Portland, Oregon, 1974.

[7] Mandel, H. Standortfragen bei Kernkraftwerken. Atomwirtschaft. Vol.16 (1971), pp.22-26.

[8] Candes, P. Practice and Experience of Safety in Nuclear Plant Siting in France. In Transactions of the American Nuclear Society Conference on Nuclear Power Plant Siting, Portland, Oregon, 1974, pp.4-5.

[9] Norris, J.A. The Guide to Siting of Nuclear Power Plants. In Transactions of the American Nuclear Society Conference on Nuclear Power Plant Siting, Portland, Oregon, $1974, \mathrm{pp} .6-7$.

[10] Bock, H. Standortkriterien fur Kernkraftwerke. Elektrotechnik und Maschinenbau, Vol. 91 (1974), pp.312-315.

[11] Hill, M., and R.Altermann. Power Plant Site Evaluation: the Case of the Sharon Plant in Israel. Journal of Environmental Management. Vol.2 (1974), pp.179-196. 
[12] Beer, L.P. Quantification of Siting Factors for Rational Selection of Alternative Sites. In Transactions of the American Nuclear Society Conference Power Plant Siting, Portland, Oregon, 1974, pp.12-14.

[13] U.S.Environmental Protection Agency, Office of Radiation Programs. Environmental Analysis of the Uranium Fuel Cycle, Part II - Nuclear Power Reactors, Washington, D.C., November 1973.

[14] Anderson, D. Models for Determining Least Cost Investments in Electricity Supply. The Bell Journal of Economics and Management Science, 3 (1972), pp.267-299.

[15] Gros, J. A Paretian Approach to Power Plant Siting in New England. Ph.D. dissertation, Harvard University, May 1974 .

[16] McCusker, K., Baecher, G., and J.Gros. State of the Art of Multi-Objective Decision Making Techniques for Nuclear Facilities Siting. IIASA Research Report forthcoming.

[17] Pochin, E.E. The Development of Quantitative Bases for Radiation Protection. In Environmental Aspects of Nuclear Power Stations. International Atomic Energy Agency, Vienna, 1971, pp.119-125.

[18] Beattie, J. Rationale of Reactor Site Selection for Public Safety. In Transactions of the American Nu clear Society Conference on Nuclear Power Plant Siting, Portland, Oregon, 1974, pp.15-16.

[19] Majone, G. On the Logic of Standard Setting in Health and Related Fields. In Proceedings of the IIASA Conference on Systems Aspects of Health Planning. Mark Thompson, ed. forthcoming.

[20] Institut für Reaktorsicherheit. Sicherheitskriterien für Kernkraftwerke, Report number IRS-R-2, May 1969.

[21] Atomwirtschaft. Kernkraftwerk Biblis, Vol.19 (1974), pp. $406-438$.

[22] Dorfman, R., and H.D.Jacoby. An Illustrative Model of River Basin Pollution Control. In Models for Managing Regional Water Quality, R. Dorfman, H.D. Jacoby, and H.A.Thomas, Jr., eds. Cambridge, Massachusetts, Harvard University Press, 1972.

[23] Gros, J. Power Plant Siting: A Paretian Environmental Approach. Discussion Paper No.74-4, Environmental Systems Program, Harvard University, Cambridge, Massachusetts, August 1974. 
[24] Keeney, Ralph L. Multiplicative Utility Functions. Technical Report No. 70, Operations Research Center, Massachusetts Institute of Technology, 1972.

[25] Keeney, Ralph L, and Na1r, Keshavan. Decision Analysis for Siting of Nuclear Power Plants: The Relevance of Multiattribute Utility Theory. Technical Report No. 96, Operations Research Center, Massachusetts Institute of Technology, June 1974. 